\title{
A New MPPT Method for Low-Power Solar Energy Harvesting
}

\author{
Oscar López-Lapeña, Maria Teresa Penella, Student Member, IEEE, and \\ Manel Gasulla, Member, IEEE
}

\begin{abstract}
This paper describes a new maximum-power-pointtracking (MPPT) method focused on low-power $(<1 \mathrm{~W})$ photovoltaic (PV) panels. The static and dynamic performance is theoretically analyzed, and design criteria are provided. A prototype was implemented with a $500-\mathrm{mW}$ PV panel, a commercial boost converter, and low-power components for the MPPT controller. Laboratory measurements were performed to assess the effectiveness of the proposed method. Tracking efficiency was higher than $99.6 \%$. The overall efficiency was higher than $92 \%$ for a PV panel power higher than $100 \mathrm{~mW}$. This is, in part, feasible due to the low power consumption of the MPPT controller, which was kept lower than $350 \mu \mathrm{W}$. The time response of the tracking circuit was tested to be around $1 \mathrm{~s}$. Field measurements showed energy gains higher than $10.3 \%$ with respect to a direct-coupled solution for an ambient temperature of $26{ }^{\circ} \mathrm{C}$. Higher gains are expected for lower temperatures.
\end{abstract}

Index Terms-Energy harvesting, maximum power point tracking (MPPT), solar cells, wireless sensor networks (WSNs).

\section{INTRODUCTION}

$\mathbf{L}$ OW-POWER devices mainly use either primary or secondary (rechargeable) batteries. Primary batteries are cheaper and are suitable whenever they survive the life cycle of the device. On the other hand, secondary batteries are used in mobile devices that must often be recharged from the mains, such as, for example, mobile phones. However, in some devices, such as the nodes of wireless sensor networks (WSNs), this solution is not practical. Energy harvesting constitutes a feasible alternative and has been proposed in order to power autonomous nodes using optical [1], [2], mechanical [3], or thermal energy [4] or even a combination of them [5]. Among the ambient sources, optical (or solar) energy provides high power density, principally outdoors.

In order to extract the maximum power from a photovoltaic (PV) panel, several maximum-power-point-tracking (MPPT) methods have been proposed and used for high-power systems [6]. Their application to low-power PV panels $(<1 \mathrm{~W})$ has just

Manuscript received December 31, 2008; revised May 8, 2009, June 29, 2009, September 25, 2009, and October 26, 2009; accepted November 10, 2009. Date of publication December 4, 2009; date of current version August 11, 2010. This work was supported in part by the Spanish Ministry of Education and Science under Contract TEC2007-66331/MIC, by the European Regional Development Fund, and by the Spanish-Tunisian Cooperation Project (AECI-A/01218207). The work of M. T. Penella was supported by the Ministry of Education and Science of Spain under the FPU Program (AP2005-2508).

The authors are with the Instrumentation, Sensors and Interfaces Group, Universitat Politècnica de Catalunya, 08860 Barcelona, Spain (e-mail: oscar@eel.upc.edu; mpenella@eel.upc.edu; manel.gasulla@upc.edu).

Color version of one or more figures in this paper are available online at http://ieeexplore.ieee.org.

Digital Object Identifier 10.1109/TIE.2009.2037653

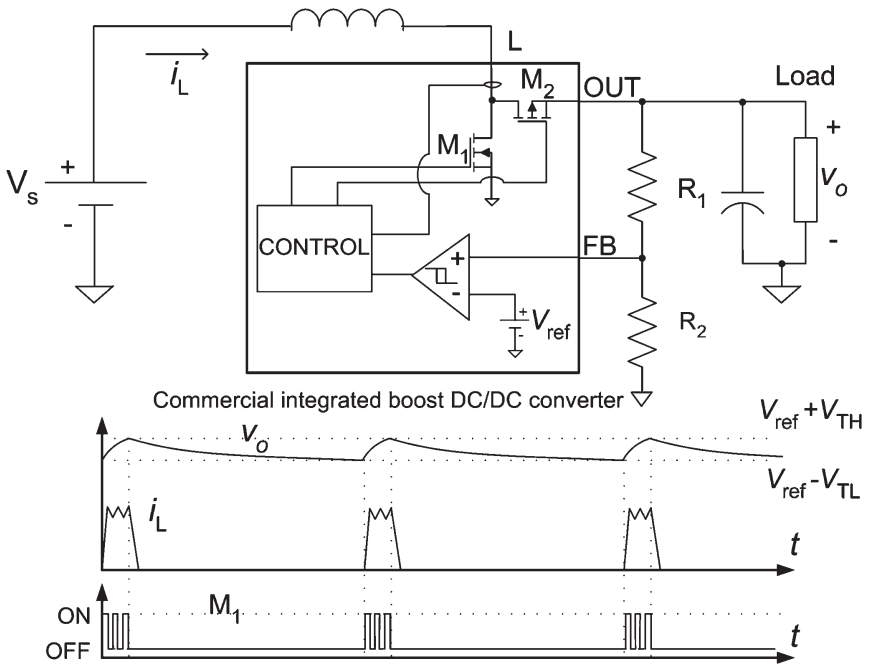

Fig. 1. PFM technique for a boost regulator at light loads.

recently been proposed [7]-[10] and poses new challenges to achieve a net power gain. In contrast to high-power applications, the power consumption of the MPPT control circuit can contribute significantly to the final power efficiency. This paper proposes and implements a new MPPT method that is particularly suitable for these low-power source levels. The method does not require complex operations and can be implemented with low-power components.

\section{BACKGROUND}

\section{A. Energy Harvesting}

The autonomous nodes of a WSN are composed of sensing, processing, and communication stages. Power consumption usually ranges from tens of milliwatts when fully active to units of microwatts in sleep mode. When the power is provided by the environment [11], a transducer, e.g., a PV panel, converts ambient energy into electrical energy, with a given efficiency. For perpetual operation, the harvested power must be higher, in average, than the consumed power of the node. An energy storage unit, e.g., a rechargeable battery, must account for the variability of the ambient energy. Finally, an energyconditioning block matches the transducer to the storage unit.

\section{B. DC/DC Conversion and PFM Control}

Direct-coupled solutions use a single diode to connect the PV panel to the storage unit. More elaborated designs use instead a $\mathrm{dc} / \mathrm{dc}$ converter in order to work at the maximum power 


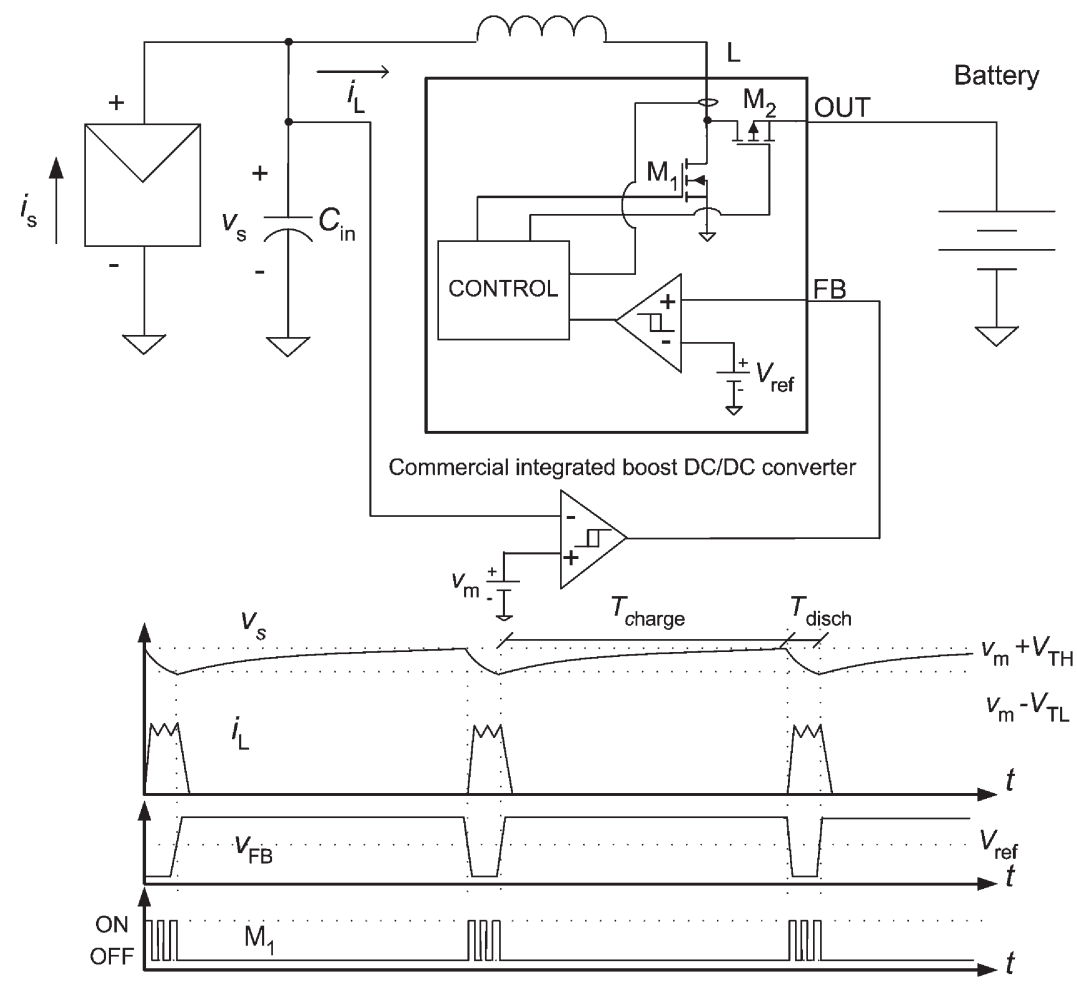

Fig. 2. PFM technique applied to the energy-conditioning block of solar energy harvesters.

point (MPP: $I_{\mathrm{MPP}}, V_{\mathrm{MPP}}$ ) and then increase the harvested energy [12].

Switching converters are the most energy-efficient dc/dc regulators, and plenty of commercial off-the-shelf (COTS) components are available. Pulse frequency modulation (PFM) control techniques, which are based on a hysteresis control of the output voltage, are used to achieve a low power consumption of the converter and then a high efficiency with light loads [13]. Fig. 1 shows a schematic of a PFM boost regulator, together with the temporal evolution of the output voltage $\left(v_{\mathrm{o}}\right)$, the inductor current $\left(i_{\mathrm{L}}\right)$, and the control signal of the internal switch $\mathbf{M}_{1}$. Switches $\mathrm{M}_{1}$ and $\mathrm{M}_{2}$ are off until $v_{\mathrm{O}}$ falls below a low threshold value $\left(V_{\mathrm{ref}}-V_{\mathrm{TL}}\right)$. Then, the switches alternately activate in order to transfer electrical charge from the input to the output until $v_{\mathrm{O}}$ reaches a high threshold value $\left(V_{\text {ref }}+V_{\mathrm{TH}}\right)$, restarting the process. For light loads, the inactive period increases, which maintains a low overall power consumption and a high efficiency.

We propose to use the same PFM technique, using COTS components, in the energy-conditioning block of solar energy harvesters (Fig. 2). Now, an input capacitor $\left(C_{\text {in }}\right)$ is connected in parallel with the PV panel, and an external hysteresis comparator is placed between the panel and the feedback (FB) terminal of the dc/dc converter. First, during a time $T_{\text {charge }}$, switches $\mathrm{M}_{1}$ and $\mathrm{M}_{2}$ are off, and the current of the PV panel $\left(i_{\mathrm{s}}\right)$ charges $C_{\text {in }}$ until the voltage of the PV panel $\left(v_{\mathrm{s}}\right)$ reaches $v_{\mathrm{m}}+V_{\mathrm{TH}}$. Then, $V_{\mathrm{FB}}$ toggles, and the converter switches $\mathrm{M}_{1}$ and $\mathrm{M}_{2}$ alternately activate, during a time $T_{\text {disch }}$, in order to transfer charge from $C_{\text {in }}$ to the output until $v_{\mathrm{s}}$ decreases to $v_{\mathrm{m}}-V_{\mathrm{TL}}$, restarting the process. The voltage operating point of the PV panel is determined by $v_{\mathrm{m}}$. To reach the MPP, $v_{\mathrm{m}}$ must be obtained from an MPPT controller.
In Figs. 1 and 2, a boost converter has been shown for illustration, but the same concepts can be applied to buck or buck-boost converters.

\section{Low-Power MPPT Methods}

An MPPT controller that is suitable for low-power PV panels must have low power consumption. Then, low computation complexity and low-power components are preferred.

One of the simplest MPPT methods is the fractional opencircuit voltage (FOCV), which exploits the nearly linear relationship between the PV panel open-circuit voltage $\left(V_{\mathrm{OC}}\right)$ and its voltage at the MPP ( $\left.V_{\mathrm{MPP}}\right)$ under varying irradiance and temperature levels. However, this result is based on observations and must be empirically determined for each specific type of PV panel [14]. $V_{\text {OC }}$ is either measured periodically by momentarily opening the output of the PV panel, as that in [9], or by using a pilot cell (an additional PV panel of the same type in an OCV configuration), as that in [8].

A more elaborated method is the perturb and observe $(\mathrm{P} \& \mathrm{O})$ method, as that in [7]. The basic idea is to slightly perturb the operating voltage of the PV panel and see how the power changes. If the power increases, the perturbation should be kept in the same direction; otherwise, it should be reversed. To compute power, current and voltage measurements must be usually performed. Overall, a true MPPT is achieved at the expense of increasing the circuit complexity and the power consumption with respect to the FOCV method.

Recently, a new low-complexity technique has been proposed [15]. However, the method has only been tested in a (relatively high power) 55-W PV panel and presents a poor tracking efficiency for low-power irradiation levels. 


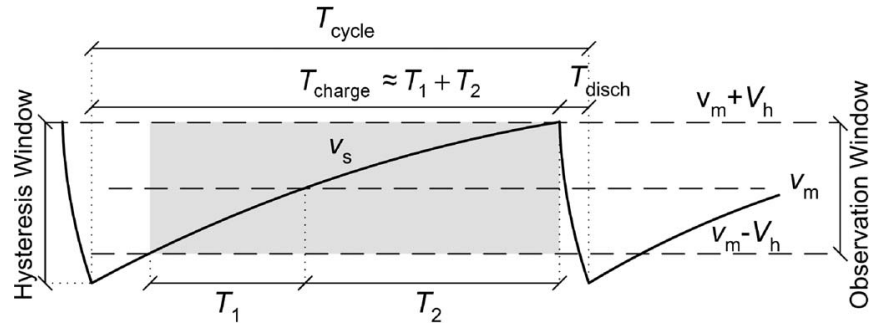

Fig. 3. Observation and hysteresis windows of the proposed MPPT method.

\section{Proposed MPPT Method}

\section{A. Theoretical Approach}

A true MPPT method must measure the generated power of the PV panel and find and follow its maximal value. Here, we propose to use the circuit described in Fig. 2 in combination with a new proposed MPPT technique well suited for lowpower PV panels. In order to achieve the MPP, the method nulls the difference of the panel average power in two consecutive time intervals $\left(T_{1}\right.$ and $\left.T_{2}\right)$ within $T_{\text {charge. }}$. As Fig. 3 shows, $T_{1}$ and $T_{2}$ correspond to the lower and upper halves, respectively, of an observation voltage window (whose gap is $2 V_{\mathrm{h}}$ ) centered on the operating voltage $v_{\mathrm{m}}$. As can be seen, the minimum voltage of the observation window is slightly higher than the minimum voltage of the hysteresis window to let the devices used in the MPPT controller (see Section III-B) to overcome the transient response produced by the fast discharge of $C_{\mathrm{in}}$. On the other hand, the upper limits of the hysteresis and observation windows match. For the sake of simplicity, we will assume in the rest of this paper that both windows match and that $T_{\text {charge }} \approx T_{1}+T_{2}$.

Referring to Fig. 3, the period of $v_{\mathrm{s}}$ is given by

$$
T_{\text {cycle }}=T_{\text {charge }}+T_{\text {disch }} \text {. }
$$

As the converter is inactive during $T_{\text {charge }}$, the output power of the PV panel $\left(P_{\mathrm{s}}\right)$ is equal to the incoming power at $C_{\mathrm{in}}$; then,

$$
P_{\mathrm{s}}=v_{\mathrm{s}} i_{\mathrm{s}}=v_{\mathrm{s}} C_{\mathrm{in}} \frac{d v_{\mathrm{s}}}{d t} .
$$

The average power results in

$$
\bar{P}_{\mathrm{s}}=\frac{1}{T} \int_{t_{0}}^{t_{0}+T} P_{\mathrm{s}} d t=\frac{C_{\mathrm{in}}}{T} \int_{v_{\mathrm{s}}\left(t_{0}\right)}^{v_{\mathrm{s}}\left(t_{0}+T\right)} v_{\mathrm{s}} d v_{\mathrm{s}}
$$

where $t_{0}$ and $T$ are an arbitrary time instant and a time interval within $T_{\text {charge }}$, respectively. Applying (3) into the calculation of the average power during $T_{1}$ and $T_{2}$ results in

$$
\begin{aligned}
& \bar{P}_{\mathrm{s} 1}=\frac{C_{\mathrm{in}}}{T_{1}} \int_{v_{\mathrm{m}}-V_{\mathrm{h}}}^{v_{\mathrm{m}}} v_{\mathrm{s}} d v_{\mathrm{s}}=\frac{C_{\mathrm{in}} V_{\mathrm{h}}}{T_{1}}\left(v_{\mathrm{m}}-\frac{V_{\mathrm{h}}}{2}\right) \\
& \bar{P}_{\mathrm{s} 2}=\frac{C_{\mathrm{in}}}{T_{2}} \int_{v_{\mathrm{m}}}^{v_{\mathrm{m}}+V_{\mathrm{h}}} v_{\mathrm{s}} d v_{\mathrm{s}}=\frac{C_{\mathrm{in}} V_{\mathrm{h}}}{T_{2}}\left(v_{\mathrm{m}}+\frac{V_{\mathrm{h}}}{2}\right) .
\end{aligned}
$$

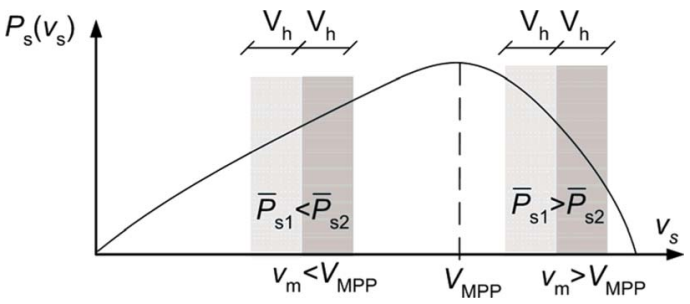

Fig. 4. Evaluation of the operating point $\left(v_{\mathrm{m}}\right)$ with respect to the MPP $\left(V_{\mathrm{MPP}}\right)$.

From (4), the power difference is

$\Delta P_{\mathrm{s}} \equiv \bar{P}_{\mathrm{s} 2}-\bar{P}_{\mathrm{s} 1}=\frac{C_{\mathrm{in}} V_{\mathrm{h}}}{T_{2} T_{1}}\left(v_{\mathrm{m}}\left(T_{1}-T_{2}\right)+\frac{V_{\mathrm{h}}}{2}\left(T_{1}+T_{2}\right)\right)$.

The sign of (5) will indicate the position of the operating voltage $v_{\mathrm{m}}$ with respect to $V_{\mathrm{MPP}}$. Fig. 4 shows the characteristic power profile versus the operating voltage of a generic PV panel $(P-V$ curve) and illustrates this concept. As can be seen, whenever (5) is positive, $v_{\mathrm{m}}<V_{\mathrm{MPP}}$ and should be increased. On the other hand, whenever (5) is negative, $v_{\mathrm{m}}>V_{\mathrm{MPP}}$ and should be decreased. The sign of (5) depends exclusively on the term within the parentheses. This term will be defined as $L\left(v_{\mathrm{m}}\right)$

$$
L\left(v_{\mathrm{m}}\right) \equiv v_{\mathrm{m}}\left(T_{1}-T_{2}\right)+\frac{V_{\mathrm{h}}}{2}\left(T_{1}+T_{2}\right) .
$$

An equilibrium point $v_{\mathrm{m}, \mathrm{eq}}$ will be achieved when $\Delta P_{\mathrm{s}}=$ 0, i.e.,

$$
L\left(v_{\mathrm{m}, \mathrm{eq}}\right)=v_{\mathrm{m}, \mathrm{eq}}\left(T_{1}-T_{2}\right)+\frac{V_{\mathrm{h}}}{2}\left(T_{1}+T_{2}\right)=0
$$

resulting in $v_{\mathrm{m}, \mathrm{eq}}=V_{\mathrm{MPP}}$ if $V_{\mathrm{h}} \ll V_{\mathrm{MPP}}$.

\section{B. Implementation}

To implement the MPPT control law, we propose to calculate $v_{\mathrm{m}}$ as the iterative sum of $L\left(v_{\mathrm{m}}\right)$ in each new cycle

$$
\begin{array}{r}
v_{\mathrm{m}}(n)=\frac{1}{\tau_{\mathrm{INT}}} \sum_{i=1}^{n-1}\left(\int_{T_{1}(i)} v_{\mathrm{m}}(i) d t-\int_{T_{2}(i)} v_{\mathrm{m}}(i) d t\right. \\
\left.+\int_{T_{1}(i)+T_{2}(i)} \frac{V_{\mathrm{h}}}{2} \cdot d t\right)
\end{array}
$$

where $v_{\mathrm{m}}(n)$ is sampled at the end of each $T_{\text {charge }}, \tau_{\mathrm{INT}}$ is an integral constant, and $n$ is the cycle number. As can be seen, the multiplication operations in (6) have been replaced by integral operators. This equivalence is based on the fact that $V_{\mathrm{h}}$ is a constant and that the sampled $v_{\mathrm{m}}$ has a constant value during $T_{1}$ and $T_{2}$. Moreover, in contrast to other methods, the measurement of the current is not required. The value of $v_{\mathrm{m}}$ will increase whenever $v_{\mathrm{m}}(n)<V_{\mathrm{MPP}}$ and will decrease whenever $v_{\mathrm{m}}(n)>V_{\mathrm{MPP}}$, thus tending to $v_{\mathrm{m}, \mathrm{eq}} \approx V_{\mathrm{MPP}}$.

Fig. 5 shows the schematic diagram of the implemented MPPT circuit. Comparator $\mathrm{CMP}_{2}$ toggles $\mathrm{SW}_{2}$ at the instant 


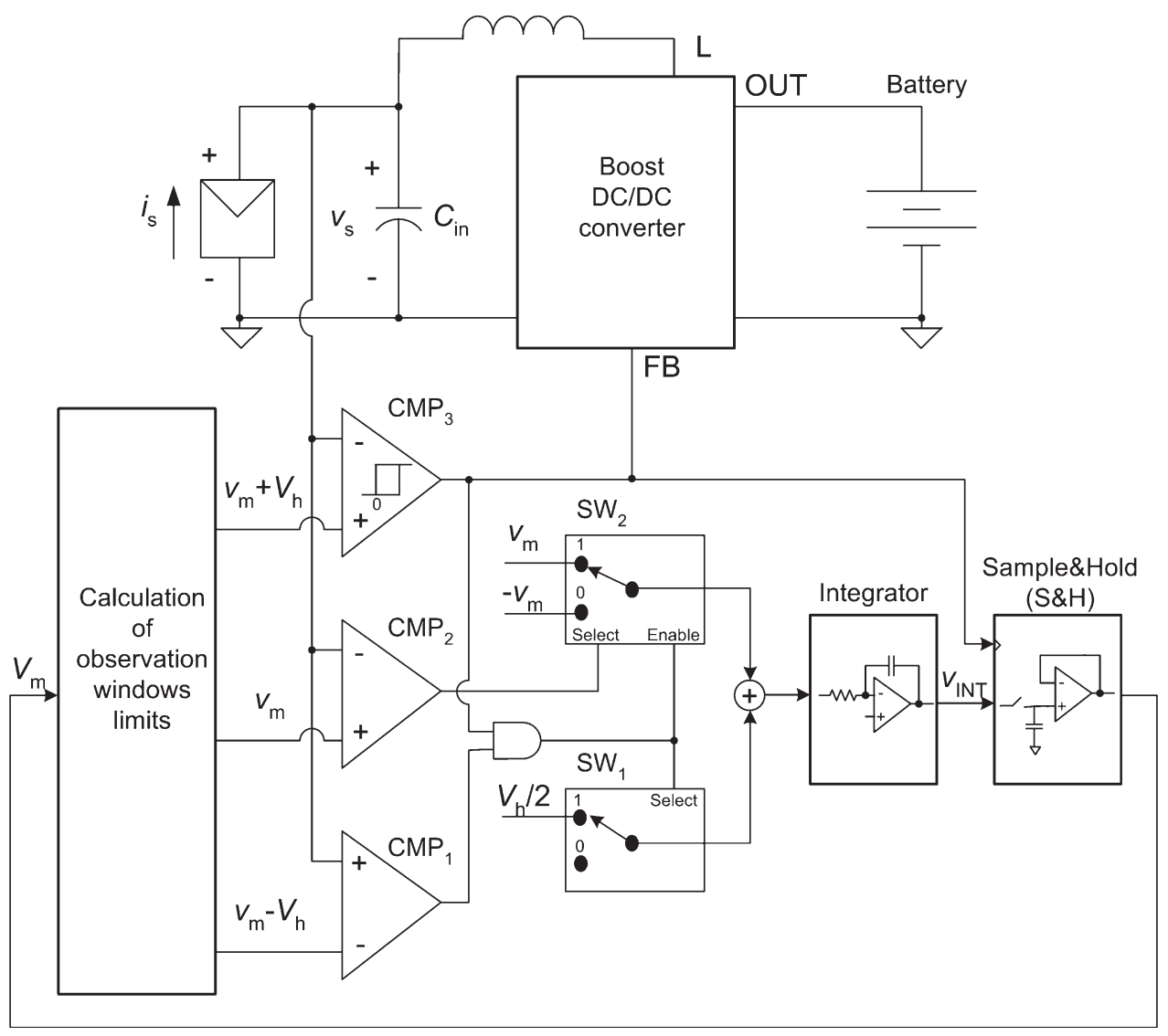

Fig. 5. Simplified schematic of the energy conditioner with the proposed MPPT control circuit.

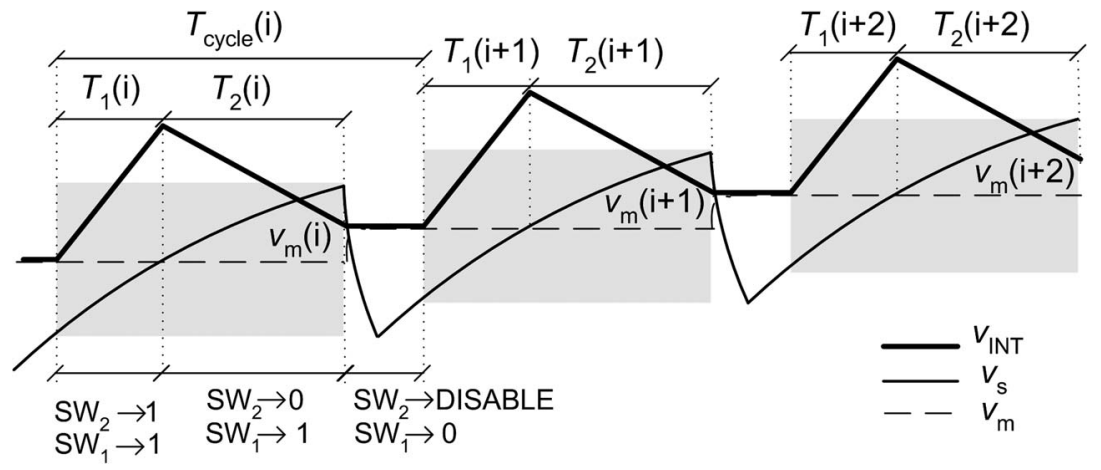

Fig. 6. Expected temporal evolution of $v_{\mathrm{m}}, v_{\mathrm{s}}$, and $v_{\mathrm{INT}}$, for the case in which $v_{\mathrm{m}}<V_{\mathrm{MPP}}$.

time $v_{\mathrm{s}}$ crosses $v_{\mathrm{m}}$. Hysteresis comparator $\mathrm{CMP}_{3}$ activates the converter during $T_{\text {disch }}$. This same comparator, together with $\mathrm{CMP}_{1}$, enables $\mathrm{SW}_{2}$ and selects terminal 1 of $\mathrm{SW}_{1}$ during $T_{1}$ and $T_{2}$. The output signals of $\mathrm{SW}_{1}$ and $\mathrm{SW}_{2}$ are added and integrated, and the resulting output $v_{\mathrm{INT}}$ is sampled at the end of $T_{\text {charge, }}$, providing a new value of $v_{\mathrm{m}}$. Fig. 6 shows the expected temporal evolution of $v_{\mathrm{m}}, v_{\mathrm{s}}$, and $v_{\mathrm{INT}}$, for the case in which $v_{\mathrm{m}}<V_{\mathrm{MPP}}$. As can be seen, $v_{\mathrm{m}}$ is updated at the end of $T_{\text {charge }}$ and increases toward $V_{\mathrm{MPP}}$. The state of $\mathrm{SW}_{1}$ and $\mathrm{SW}_{2}$ during a whole cycle is also shown.

\section{ANALYSIS}

In order to achieve an optimum design, the static and dynamic MPPT performance will be theoretically analyzed. Static performance will be assessed by the overall power efficiency, which can be split up into three terms

$$
\eta_{\mathrm{T}} \equiv \eta_{\mathrm{MPPT}} \cdot \eta_{\mathrm{av}} \cdot \eta_{\mathrm{c}}
$$

where $\eta_{\mathrm{MPPT}} \equiv\left(P_{\mathrm{s}}\left(v_{\mathrm{m}, \text { eq }}\right) / P_{\mathrm{MPP}}\right), \eta_{\mathrm{av}} \equiv\left(\bar{P}_{\mathrm{s}} / P_{\mathrm{s}}\left(v_{\mathrm{m}, \text { eq }}\right)\right)$, and $\eta_{\mathrm{c}} \equiv\left(\bar{P}_{\mathrm{out}} \overline{P_{\mathrm{s}}}\right) ; P_{\mathrm{MPP}}$ and $P_{\mathrm{s}}\left(v_{\mathrm{m}, \text { eq }}\right)$ are the $\mathrm{PV}$ power at the MPP and at $v_{\mathrm{m}, \text { eq }}$, respectively; $\bar{P}_{\mathrm{s}}$ and $\bar{P}_{\text {out }}$ are the average power at the input and output of the dc/dc converter, respectively.

On the other hand, the dynamic performance will be assessed by the time constant of $v_{\mathrm{m}}$ modeled as a first-order time function.

\section{A. Efficiency of the MPPT Algorithm ( $\left.\eta_{\mathrm{MPPT}}\right)$}

The goal of the proposed MPPT controller is to achieve high tracking efficiency with low power consumption. The 


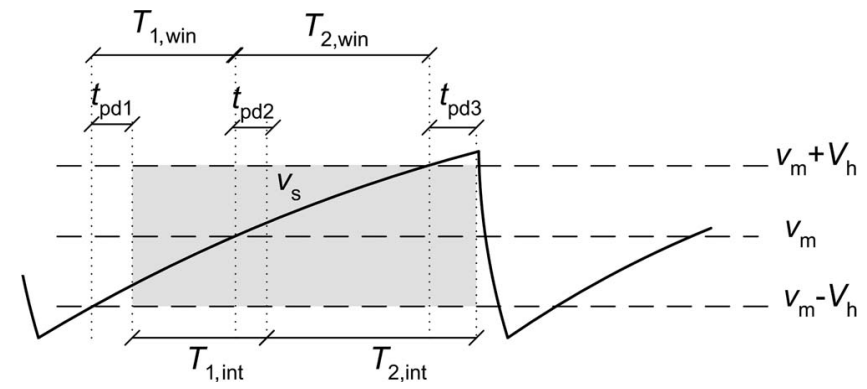

Fig. 7. Definition of the time intervals when the propagation delays of the comparators are taken into account.

propagation delays of the comparators $\mathrm{CMP}_{1}-\mathrm{CMP}_{3}$ (Fig. 5) will affect the tracking efficiency. This is of particular relevance due to the design tradeoff between the power consumption and the propagation delay of COTS comparators. In the following, we analyze how these delays affect the tracking efficiency.

Fig. 7 shows the observation window considering the propagation delays $t_{\mathrm{pd} 1}, t_{\mathrm{pd} 2}$, and $t_{\mathrm{pd} 3}$ introduced by $\mathrm{CMP}_{1}, \mathrm{CMP}_{2}$, and $\mathrm{CMP}_{3}$, respectively.

The relationship between the different time intervals is given by

$$
\begin{aligned}
& T_{1, \text { int }}=T_{1, \text { win }}-t_{\mathrm{pd} 1}+t_{\mathrm{pd} 2} \\
& T_{2, \text { int }}=T_{2, \text { win }}-t_{\mathrm{pd} 2}+t_{\mathrm{pd} 3} .
\end{aligned}
$$

$T_{1, \text { win }}$ and $T_{2 \text {,win }}$ are the ideal interval times defined by the observation window and provide the actual $\Delta P_{\mathrm{s}}$ through (5). $T_{1, \text { int }}$ and $T_{2, \text { int }}$ are the integration times of the MPPT circuit in Fig. 5 and determine $v_{\mathrm{m}, \text { eq }}$ through (7). Therefore, due to the propagation delays, $\Delta P_{\mathrm{s}}\left(v_{\mathrm{m}, \mathrm{eq}}\right)$ will not be zero, and consequently, $v_{\mathrm{m} \text {,eq }}$ will not reach the MPP at the equilibrium point, worsening the tracking efficiency. Even so, we still assume that the equilibrium point will be near the MPP.

Substituting $T_{1}$ and $T_{2}$ in (7) by $T_{1, \text { int }}$ and $T_{2 \text {,int }}$ and using (10), we obtain

$$
\begin{aligned}
& v_{\mathrm{m}, \mathrm{eq}}\left(\left(T_{1, \mathrm{win}}-t_{\mathrm{pd} 1}+t_{\mathrm{pd} 2}\right)-\left(T_{2, \text { win }}-t_{\mathrm{pd} 2}+t_{\mathrm{pd} 3}\right)\right) \\
& \quad+\frac{V_{\mathrm{h}}}{2}\left(\left(T_{1, \operatorname{win}}-t_{\mathrm{pd} 1}+t_{\mathrm{pd} 2}\right)+\left(T_{2, \mathrm{win}}-t_{\mathrm{pd} 2}+t_{\mathrm{pd} 3}\right)\right)=0 .
\end{aligned}
$$

Then, substituting $T_{1}$ and $T_{2}$ in (5) by $T_{1, \text { win }}$ and $T_{2, \text { win }}$, using (11), and considering $V_{\mathrm{h}} \ll v_{\mathrm{m}, \text { eq }}$, we obtain

$$
\Delta P_{\mathrm{s}}\left(v_{\mathrm{m}, \mathrm{eq}}\right) \approx \frac{C_{\mathrm{in}} V_{\mathrm{h}}}{T_{1, \mathrm{win}} T_{2, \text { win }}} v_{\mathrm{m}, \mathrm{eq}}\left(t_{\mathrm{pd} 1}-2 t_{\mathrm{pd} 2}+t_{\mathrm{pd} 3}\right) .
$$

We can then relate the slope of the $P-V$ curve at the equilibrium point with the propagation delays by

$$
\begin{aligned}
\left.\frac{d P_{\mathrm{s}}}{d v_{\mathrm{s}}}\right|_{v_{\mathrm{m}, \mathrm{eq}}} & \left.\approx \frac{\Delta P_{\mathrm{s}}}{V_{\mathrm{h}}}\right|_{\substack{v_{\mathrm{m}, \mathrm{eq}} \\
V_{\mathrm{h}} \ll V_{\mathrm{MPP}}}} \\
& \approx \frac{t_{\mathrm{pd} 1}-2 t_{\mathrm{pd} 2}+t_{\mathrm{pd} 3}}{C_{\mathrm{in}} V_{\mathrm{h}}^{2}} P_{\mathrm{MPP}} I_{\mathrm{MPP}}
\end{aligned}
$$

where we considered $v_{\mathrm{m}, \mathrm{eq}} \approx V_{\mathrm{MPP}}$ and

$$
T_{1, \text { win }} \approx T_{2, \text { win }} \approx \frac{T_{\text {charge }}}{2} \approx \frac{C_{\text {in }} V_{\mathrm{h}}}{I_{\mathrm{MPP}}} .
$$

On the other hand, we can approximate $P_{\mathrm{s}}$ around $V_{\mathrm{MPP}}$ by a second-order Taylor polynomial

$$
P_{\mathrm{s}}\left(v_{\mathrm{s}}\right) \approx P_{\mathrm{MPP}}+\left.\frac{1}{2} \frac{d^{2} P_{\mathrm{s}}}{d v_{\mathrm{s}}^{2}}\right|_{V_{\mathrm{MPP}}}\left(v_{\mathrm{s}}-V_{\mathrm{MPP}}\right)^{2}
$$

Derivating (15), we obtain

$$
v_{\mathrm{s}}-V_{\mathrm{MPP}}=\frac{d P_{\mathrm{s}} /\left.d v_{\mathrm{s}}\right|_{v_{\mathrm{s}}}}{d^{2} P_{\mathrm{s}} /\left.d v_{\mathrm{s}}^{2}\right|_{V_{\mathrm{MPP}}}} .
$$

Then, substituting (15) at $v_{\mathrm{s}}=v_{\mathrm{m}, \mathrm{eq}}$ in $\eta_{\mathrm{MPPT}}$ and using (13) and (16), we obtain

$\eta_{\mathrm{MPPT}}$

$$
\approx 1+\left(\frac{t_{\mathrm{pd} 1}-2 t_{\mathrm{pd} 2}+t_{\mathrm{pd} 3}}{C_{\mathrm{in}} V_{\mathrm{h}}} \frac{I_{\mathrm{MPP}}}{V_{\mathrm{h}}}\right)^{2} /\left(\left.\frac{2}{P_{\mathrm{MPP}}} \frac{d^{2} P_{\mathrm{s}}}{d v_{\mathrm{s}}^{2}}\right|_{V_{\mathrm{MPP}}}\right) .
$$

Notice that the second derivative of $P_{\mathrm{s}}$ is negative and then $\eta_{\mathrm{MPPT}}<1$. The tracking efficiency will tend to the unity with low and matched propagation delays and with higher values of $V_{\mathrm{h}}$. A higher value of the product $C_{\mathrm{in}} V_{\mathrm{h}}$ also increases the tracking efficiency. This seems obvious from (14) since $T_{\text {charge }}$ increases and then the relative error contributed by the propagation delays diminishes.

The adaptation of the method for high-power applications would require the selection of higher values of $C_{\mathrm{in}} V_{\mathrm{h}}$ to maintain a high tracking accuracy. An alternative is to use faster comparators that, obviously, will increase the power consumption of the MPPT controller.

\section{B. Averaging Efficiency $\left(\eta_{\mathrm{av}}\right)$}

The proposed MPPT method implies that $P_{\mathrm{S}}$ fluctuates around $P_{\mathrm{s}}\left(v_{\mathrm{m}, \mathrm{eq}}\right)$ and, as a consequence, $\bar{P}_{\mathrm{s}}<P_{\mathrm{s}}\left(v_{\mathrm{m}, \mathrm{eq}}\right)$ whenever $v_{\mathrm{m}, \mathrm{eq}} \approx V_{\mathrm{MPP}}$. From (3) and (4)

$$
\bar{P}_{\mathrm{s}}=\frac{1}{T} \int_{T_{\mathrm{cycle}}} P_{\mathrm{s}} d t \approx \frac{T_{1} \bar{P}_{\mathrm{s} 1}+T_{2} \bar{P}_{\mathrm{s} 2}}{T_{1}+T_{2}}=\frac{2 C_{\mathrm{in}} v_{\mathrm{m}, \mathrm{eq}} V_{\mathrm{h}}}{T_{1}+T_{2}}
$$

and from (2), assuming that $v_{\mathrm{m}, \mathrm{eq}} \approx V_{\mathrm{MPP}}$,

$$
T_{1}+T_{2}=\int_{T_{1}+T_{2}} d \tau=\int_{V_{\mathrm{MPP}}-V_{\mathrm{h}}}^{V_{\mathrm{MPP}}+V_{\mathrm{h}}} \frac{v_{\mathrm{s}} C_{\mathrm{in}}}{P_{\mathrm{s}}} d v_{\mathrm{s}} .
$$

Using (15) and (19) in (18) and considering $P_{\mathrm{S}}\left(v_{\mathrm{m}, \mathrm{eq}}\right) \approx$ $P_{\mathrm{MPP}}$, we arrive at

$$
\eta_{\mathrm{av}} \approx 1+\left.\frac{1}{6} \frac{1}{P_{\mathrm{MPP}}} \frac{d^{2} P_{\mathrm{s}}}{d v_{\mathrm{s}}^{2}}\right|_{V_{\mathrm{MPP}}} V_{\mathrm{h}}^{2} .
$$

Then, a larger value of $V_{\mathrm{h}}$ diminishes $\eta_{\mathrm{av}}$ because of the larger variations of $P_{\mathrm{s}}$ around $P_{\mathrm{s}}\left(v_{\mathrm{m}, \mathrm{eq}}\right)$. 


\section{Efficiency of the Circuit $\left(\eta_{\mathrm{c}}\right)$}

Considering the average circuit losses $\left(\bar{P}_{L}\right)$, the average output power is given by

$$
\bar{P}_{\text {out }}=\bar{P}_{\mathrm{s}}-\bar{P}_{L}
$$

where $\bar{P}_{L}$ accounts for the power losses of the dc/dc converter $\left(\bar{P}_{L, \text { conv }}\right)$ and the MPPT control circuit $\left(\bar{P}_{L, \mathrm{MPPT}}\right)$.

On the one hand, $\bar{P}_{L, \text { conv }}$ can be expressed as

$$
\bar{P}_{L, \mathrm{conv}}=\frac{P_{L, \mathrm{conv}-\mathrm{off}} T_{\mathrm{charge}}+P_{L, \mathrm{conv}-\mathrm{on}} T_{\mathrm{disch}}}{T_{\text {cycle }}}
$$

where $P_{L, \text { conv-on }}$ and $P_{L, \text { conv-off }}$ are the power losses when the converter is active $\left(T_{\text {disch }}\right)$ and inactive $\left(T_{\text {charge }}\right)$, respectively.

On the other hand, $\bar{P}_{L, \mathrm{MPPT}}$ can be expressed as [16]

$$
\bar{P}_{L, \mathrm{MPPT}}=P_{L, \mathrm{MPPT}-\mathrm{dc}}+\frac{K}{T_{\text {cycle }}}
$$

where $P_{L, \mathrm{MPPT} \text {-dc }}$ accounts for the static power losses and the remaining term, where $K$ is a constant, accounts for the increased switching activity of the MPPT controller as $T_{\text {cycle }}$ decreases.

Considering that the power balance in the input capacitor during a whole cycle can be expressed as

$$
\bar{P}_{\text {disch }} T_{\text {disch }}=\bar{P}_{\mathrm{s}} T_{\text {cycle }}
$$

where $\bar{P}_{\text {disch }}$ is the average power transferred from the capacitor to the converter during $T_{\text {disch }}$, and using (18) and (21)-(23), we get

$$
\begin{aligned}
\eta_{\mathrm{c}} \approx 1-( & \frac{P_{L, \text { conv-off }}+P_{L, \mathrm{MPPT}-\mathrm{dc}}}{\bar{P}_{\mathrm{s}}} \\
+ & \left.\frac{P_{L, \text { conv-on }}-P_{L, \text { conv-off }}}{\bar{P}_{\text {disch }}}+\frac{K\left(1-\bar{P}_{\mathrm{s}} / \bar{P}_{\text {disch }}\right)}{2 \cdot V_{\mathrm{MPP}}\left(C_{\mathrm{in}} V_{\mathrm{h}}\right)}\right) .
\end{aligned}
$$

For low $\bar{P}_{\mathrm{S}}$ values, the contribution of the power losses of the MPPT control circuit $\left(\bar{P}_{L, \mathrm{MPPT}}\right)$ and the converter $\left(P_{L, \text { conv-off }}\right)$ becomes significant. Otherwise, for high $\bar{P}_{\mathrm{s}}$ values, the efficiency of the converter $\left(\bar{P}_{L, \text { conv-on }}\right)$ becomes dominant. On the other hand, for a given $\bar{P}_{\mathrm{s}}, \eta_{\mathrm{c}}$ increases for larger values of the product $C_{\mathrm{in}} V_{\mathrm{h}}$.

\section{Dynamic Performance}

The dynamic response of $v_{\mathrm{m}}$ can be described by a time continuous function if $T_{\text {cycle }}$ is short enough. Then,

$$
\frac{d v_{\mathrm{m}}}{d t} \approx \frac{v_{\mathrm{m}}(n+1)-v_{\mathrm{m}}(n)}{T_{\text {cycle }}} .
$$

From (5) and (8), we obtain

$$
v_{\mathrm{m}}(n+1)-v_{\mathrm{m}}(n)=\frac{T_{2}(n) \cdot T_{1}(n)}{\tau_{\mathrm{INT}} C_{\mathrm{in}}} \frac{\Delta P_{\mathrm{s}}\left(v_{\mathrm{m}}(n)\right)}{V_{\mathrm{h}}}
$$

which, using (14) and (18), can be rewritten as

$$
\begin{aligned}
v_{\mathrm{m}}(n+1)-v_{\mathrm{m}}(n) & =\frac{T_{\text {charge }}(n)}{2 \tau_{\text {INT }}} v_{\mathrm{m}}(n) \frac{\Delta P_{\mathrm{s}}\left(v_{\mathrm{m}}(n)\right)}{\bar{P}_{\mathrm{s}}\left(v_{\mathrm{m}}(n)\right)} \\
& \left.\approx \frac{T_{\text {charge }}}{2 \tau_{\text {INT }}} V_{\mathrm{h}} v_{\mathrm{m}}\left(\frac{1}{P_{\mathrm{S}}} \frac{d P_{\mathrm{s}}}{d v_{\mathrm{s}}}\right)\right|_{v_{\mathrm{m}}} .
\end{aligned}
$$

Substituting (28) into (26), we obtain

$$
\left.\frac{d v_{\mathrm{m}}}{d t} \approx \frac{V_{\mathrm{h}}}{2 \tau_{\text {INT }}\left(1+T_{\text {disch }} / T_{\text {charge }}\right)} v_{\mathrm{m}}\left(\frac{1}{P_{\mathrm{s}}} \frac{d P_{\mathrm{s}}}{d v_{\mathrm{s}}}\right)\right|_{v_{\mathrm{m}}} .
$$

The lowest slope of $P_{\mathrm{s}}$ will be in the neighborhood of the MPP, so we can assume that the interval of time required to reach the MPP is mainly due to the dynamic response in this region. In the neighborhood of the MPP, this dynamic can be approximated by a first-order Taylor polynomial around $V_{\mathrm{MPP}}$

$$
\frac{d v_{\mathrm{m}}}{d t} \approx \frac{1}{\tau} \cdot\left(V_{\mathrm{MPP}}-v_{\mathrm{m}}\right)
$$

where, if $T_{\text {charge }} \gg T_{\text {disch }}$,

$$
\tau \approx-2 \tau_{\mathrm{INT}} /\left(\left.V_{\mathrm{h}} V_{\mathrm{MPP}} \frac{1}{P_{\mathrm{MPP}}} \frac{d^{2} P_{\mathrm{s}}}{d v_{\mathrm{s}}^{2}}\right|_{V_{\mathrm{MPP}}}\right) .
$$

Note that $T_{\text {cycle }}$ does not appear in (31), and so, it will not determine the dynamic of $v_{\mathrm{m}}$. Nevertheless, $T_{\text {cycle }}$ determines the time discretizaton of $v_{\mathrm{m}}$ (see Fig. 6). Therefore, in order to keep $T_{\text {cycle }}$ short enough, it is required that $T_{\text {charge }} \ll \tau$.

\section{Selection of Parameters}

This section describes the selection methodology of $C_{\mathrm{in}}$, $V_{\mathrm{h}}$, and $\tau_{\text {INT }}$ to reach maximum efficiency $\left(\eta_{\mathrm{T}}\right)$ with a given dynamic response. Specifically, we have selected $\tau=1 \mathrm{~s}$.

For the calculus, PV-power-related parameters, such as the second derivative of $P_{\mathrm{S}}$ and $P_{\mathrm{MPP}}$, were estimated from the experimental $P-V$ curve of the solar panel (see Section VII).

The proposed MPPT method will be tested for a given range of the PV panel power and the corresponding $I_{\mathrm{MPP}}$. From Section VI, $I_{\mathrm{MPP}, \min }=3.7 \mathrm{~mA}$, and $I_{\mathrm{MPP}, \max }=141.4 \mathrm{~mA}$.

\section{A. First Step: Selection of $C_{\mathrm{in}} V_{\mathrm{h}}$}

From (14) and imposing $T_{\text {charge }}<\tau / 10$, we get

$$
C_{\mathrm{in}} V_{\mathrm{h}}<\frac{I_{\mathrm{MPP}, \min } \tau / 10}{2}=185 \mu \mathrm{C} .
$$

Because $\eta_{\mathrm{T}}$ increases for a higher $C_{\mathrm{in}} V_{\mathrm{h}}$, we will select a value near the upper bound. We selected specifically $C_{\mathrm{in}} V_{\mathrm{h}}=$ $100 \mu \mathrm{C}$. On the other hand, (32) denotes the tradeoff between the speed of the dynamic response and the overall efficiency. The lower is the selected $\tau$, the lower will be $C_{\mathrm{in}} V_{\mathrm{h}}$ and the resulting $\eta_{\mathrm{T}}$. 


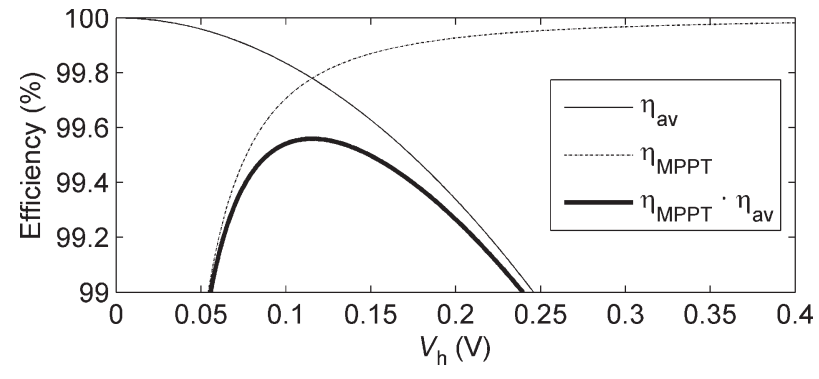

Fig. 8. Efficiencies versus $V_{\mathrm{h}}$.

\section{B. Second Step: Selection of $V_{\mathrm{h}}$}

Once the product $C_{\mathrm{in}} V_{\mathrm{h}}$ is fixed, we observe that $\eta_{\mathrm{c}}$ does not depend on the value of $V_{\mathrm{h}}$. On the other hand, $\eta_{\mathrm{MPPT}}$ increases with an increase of $V_{\mathrm{h}}$, and $\eta_{\mathrm{av}}$ decreases with an increase of $V_{\mathrm{h}}$. Therefore, the maximum of the product $\eta_{\mathrm{MPPT}} \cdot \eta_{\mathrm{av}}$ will lead to an optimum value of $V_{\mathrm{h}}$. Fig. 8 shows these efficiencies in the worst case scenario and shows the existence of a maximum around $100 \mathrm{mV}$. Therefore, we selected $V_{\mathrm{h}}=100 \mathrm{mV}$. For (17), considering the information provided in the datasheets of the comparators, we used $t_{\mathrm{pd} 1}-2 t_{\mathrm{pd} 2}+t_{\mathrm{pd} 3}=5 \mu \mathrm{s}$.

\section{Third Step: Determination of $C_{\mathrm{in}}$ and $\tau_{\mathrm{INT}}$}

From the previous selected values, we obtain $C_{\mathrm{in}}=1 \mathrm{mF}$. Finally, from (31), we obtain $\tau_{\text {INT }}=88 \mathrm{~ms}$.

\section{Materials And Methods}

A prototype of the proposed energy conditioner was implemented in order to be tested with a $500-\mathrm{mW}\left(I_{\mathrm{sc}}=\right.$ $160 \mathrm{~mA}, V_{\mathrm{OC}}=4.6 \mathrm{~V}$ ) PV panel (MSX-005, Solarex). The energy-conditioning circuit (Fig. 5) was implemented with COTS components. For the dc/dc conversion, we used a MAX1675 boost converter (PFM control with a current limit of $0.5 \mathrm{~A}$ ), a $22-\mu \mathrm{H}$ inductor, and a low-equivalentseries-resistance (ESR) $1-\mathrm{mF}$ tantalum input capacitor $\left(C_{\mathrm{in}}\right)$. LTC1440 and LTC1441 comparators were used to implement $\mathrm{CMP}_{1}, \mathrm{CMP}_{2}$, and $\mathrm{CMP}_{3}$. They provide low power $(2.1 \mu \mathrm{A})$ with a propagation delay of $12 \mu \mathrm{s}$. Low-power op amps, such as the OPA2369 and the MAX9910, were used to obtain the limits of the observation window and to amplify the input voltage $v_{\mathrm{s}}$. An OPA2369, together with the analog switch TS5A2066, was used to implement the low-power sample-and-hold. The overall control circuit was powered from the output of the boost converter.

Laboratory measurements were performed to assess the static and dynamic performance of the proposed energy conditioner. In order to achieve reproducible results, the PV panel and the battery in Fig. 5 were substituted by a PV array simulator and a voltage source, respectively. As commercial PV simulators are not suitable for the intended low power $(<1 \mathrm{~W})$, we implemented an ad hoc solution connecting a current source (GS610, Yokogawa) in parallel with the PV panel, which was coated with an opaque cover. In this way, the short-circuit current $\left(I_{\mathrm{sc}}\right)$ of the PV panel was adjusted by the current source.

First, the PV simulator was characterized. Experimental $I-V$ curves were obtained by changing the current source from 5 to
$158 \mathrm{~mA}$ in 9-mA steps. For each current value, the PV output voltage was biased from 0.1 to $5 \mathrm{~V}$ with the voltage source. The output voltages and currents of the PV simulator were measured, and power values were calculated. To obtain the $I-V$ and $P-V$ curves, we used a cubic spline interpolation. A curve joining all the MPPs was also generated. Therefore, a correspondence was established between each generated $I_{\mathrm{sc}}$ and the resulting $P_{\mathrm{MPP}}$. The limit values for $P_{\mathrm{MPP}}$ (and $I_{\mathrm{MPP}}$ ) were $8.2 \mathrm{~mW}(3.7 \mathrm{~mA})$ and $545.9 \mathrm{~mW}(141.4 \mathrm{~mA})$.

The generated $P-V$ curves were used to determine the performance of the circuit prototype. Efficiencies were obtained against the whole range of $P_{\mathrm{MPP}}$ and for different output voltages. First, $\eta_{\mathrm{MPPT}}$ was calculated by comparing the actual PV panel power $P_{\mathrm{s}}\left(v_{\mathrm{m}, \mathrm{eq}}\right)$ with $P_{\mathrm{MPP}}$ for each generated $I_{\mathrm{sc}}$ of the current source. $P_{\mathrm{s}}\left(v_{\mathrm{m}, \mathrm{eq}}\right)$ was estimated by measuring the average PV panel voltage and obtaining the corresponding power from the experimental $P-V$ curve. Then, the overall efficiency $\eta_{\mathrm{T}}$ was calculated by dividing the average output power $\left(\bar{P}_{\text {out }}\right)$ by $P_{\mathrm{MPP}} . \bar{P}_{\text {out }}$ was estimated from the measurement of the average output voltage and current. A low-ESR 100-mF supercapacitor was added at the output of the circuit in order to obtain a quasi-dc output current and then achieve a proper measurement of the power efficiency [17]. Finally, the dynamic performance of the MPPT method was assessed by programming step current changes with the current source and recording the resulting signals with an oscilloscope.

Field measurements were also carried out to compare the proposed solution with a direct-coupled solution. This one used a low-turn-on-voltage Schottky diode (BAT47) to improve its efficiency. In order to avoid differences in using two PV panels, both circuits were connected alternatively through a reed relay to a single 500-mW PV panel. Once the PV panel was connected to any of the two circuits, a 30-s delay interval lets the circuit reach the steady state before starting to record the power during $1 \mathrm{~min}$. The MPPT circuit had three AA NiMH batteries connected in series at its output, which assured that the output voltage of the boost converter was always higher than $V_{\mathrm{MPP}}$ for any irradiance level. On the other hand, the directcoupled circuit had two AA NiMH batteries connected in series at its output, in order to work near the MPP.

\section{EXPERIMENTAL RESULTS}

\section{A. Laboratory Measurements}

Fig. 9 shows a set of measured $I-V$ curves and the corresponding $P-V$ curves of the $\mathrm{PV}$ simulator at $24{ }^{\circ} \mathrm{C}$. The same graph also represents a curve joining the MPPs. As can be seen, $V_{\mathrm{MPP}}$ increases for higher $I_{\mathrm{sc}}$ values.

Fig. 10 shows how the measured power consumption (at $5 \mathrm{~V}$ ) of the MPPT control circuit increases with the input PV power. Higher PV power means a larger $I_{\mathrm{sc}}$ and then a lower $T_{\text {cycle. }}$. Therefore, the experimental results agreed with (23).

Fig. 11 shows $\eta_{\mathrm{MPPT}}$. As can be seen, $\eta_{\mathrm{MPPT}}>99.6 \%$ for the whole power range, which states the effectiveness of the proposed MPPT method and agrees with the corresponding graph in Fig. 8 for $V_{\mathrm{h}}=100 \mathrm{mV}$. Minor deviations can be observed when changing the output voltage from 5 to $4 \mathrm{~V}$. On the other hand, $\eta_{\text {av }}$ was estimated from (20) to be higher 


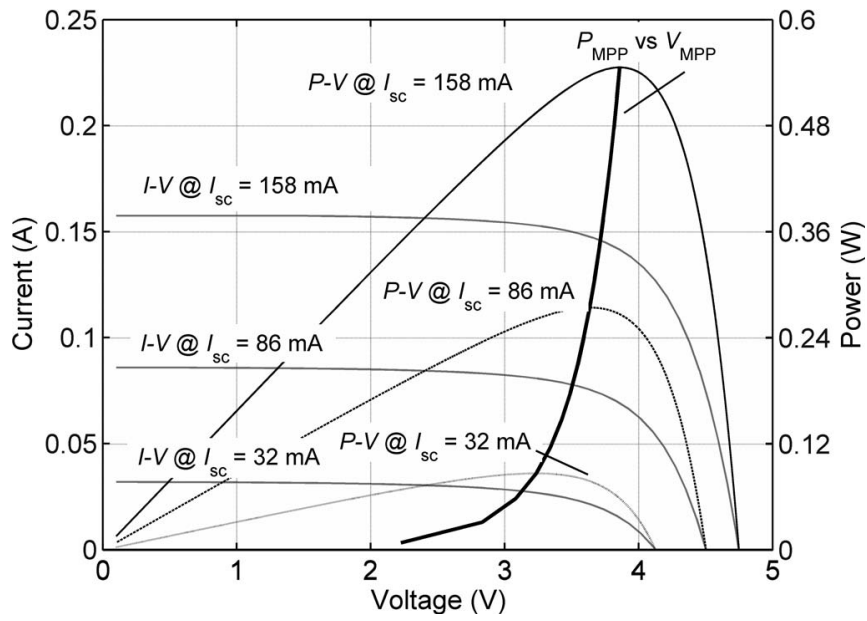

Fig. 9. $\quad I-V$ and $P-V$ curves of the PV simulator at $24{ }^{\circ} \mathrm{C}$. A curve joining the MPPs is also shown.

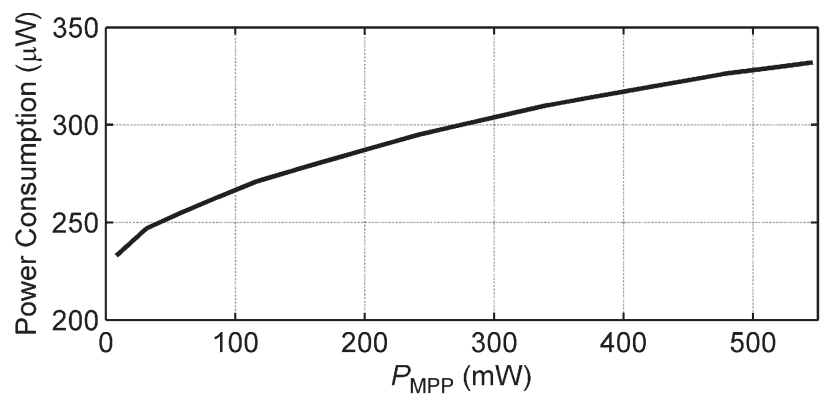

Fig. 10. Power consumption (at $5 \mathrm{~V}$ ) of the MPPT circuit versus the programmed $P_{\mathrm{MPP}}$.

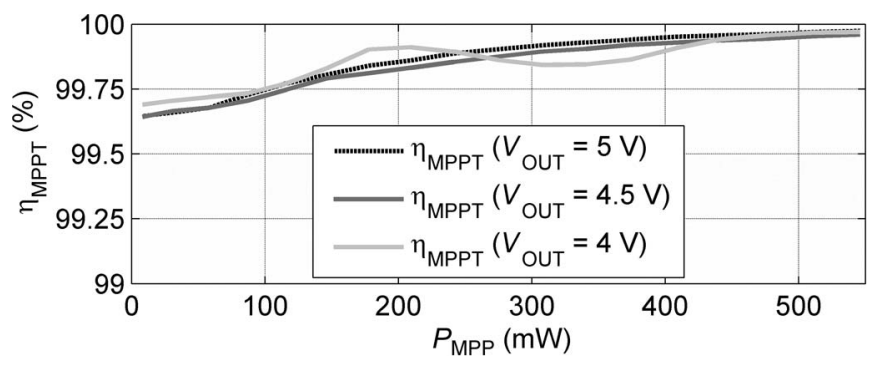

Fig. 11. $\eta_{\mathrm{MPPT}}$ versus the programmed $P_{\mathrm{MPP}}$.

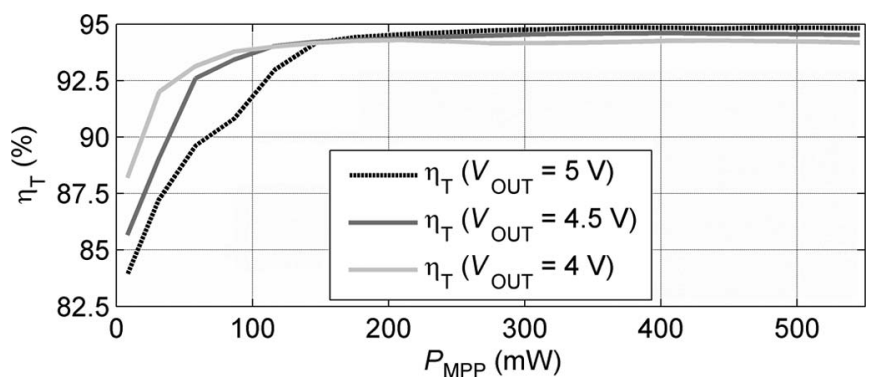

Fig. 12. $\eta_{\mathrm{T}}$ versus the programmed $P_{\mathrm{MPP}}$.

than $99.8 \%$. This value, together with the value of $\eta_{\mathrm{MPPT}}$, states that $\eta_{\mathrm{T}}$, shown in Fig. 12, is mainly due to $\eta_{\mathrm{c}}$ (not represented). These results agreed with (25), which includes the power consumption of the MPPT control circuit and the dc/dc converter.
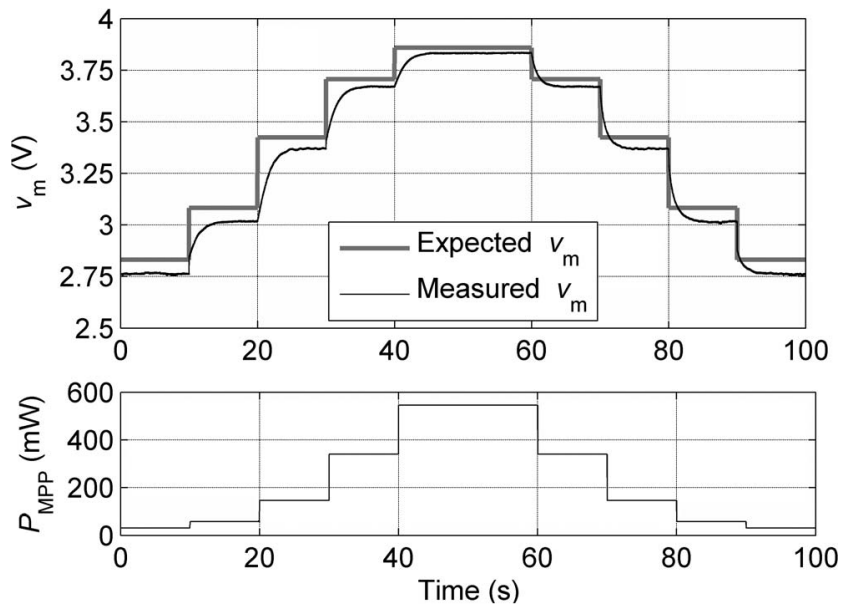

Fig. 13. Transient response of $v_{\mathrm{m}}$ to step changes of the programmed $P_{\mathrm{MPP}}$ value.

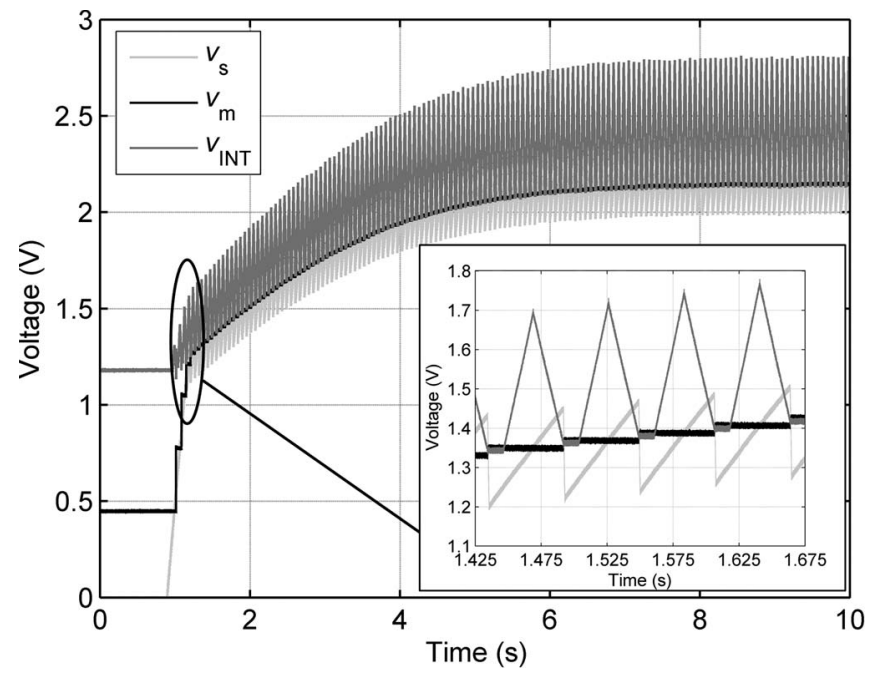

Fig. 14. MPPT startup process when $P_{\mathrm{MPP}}$ was changed from 0 to $8.2 \mathrm{~mW}$.

Fig. 13 shows the dynamic response of $v_{\mathrm{m}}$ to step changes of the programmed $P_{\mathrm{MPP}}$ value. The time constant $(\tau)$ was around $1 \mathrm{~s}$, as stated in Section V.

Fig. 14 shows the startup transient of $v_{\mathrm{INT}}, v_{\mathrm{m}}$, and $v_{\mathrm{s}}$ when $P_{\mathrm{MPP}}$ was changed from 0 to $8.2 \mathrm{~mW}$. For this test, the input capacitor $\left(C_{\text {in }}\right)$ was discharged, and the circuitry was powered from the circuit output voltage $(5 \mathrm{~V})$ some seconds prior to the zero time value of the graph. The power change was produced around $t \approx 1 \mathrm{~s}$. As can be seen, $v_{\mathrm{m}}$ and $v_{\mathrm{s}}$ fast catch $v_{\mathrm{INT}}$, which is initially settled to an internal $1.2-\mathrm{V}$ reference value. Then, the circuit behaves as a first-order system, and $v_{\mathrm{m}}$ tends to the corresponding $V_{\mathrm{MPP}}$ value. The graph inset shows with more detail the temporal evolution of the three represented signals.

\section{B. Field Measurements}

Fig. 15 shows the power delivered to the batteries during one sunny day for both the proposed MPPT circuit and the direct-coupled solution. The maximum ambient temperature and irradiance over a horizontal surface were $26{ }^{\circ} \mathrm{C}$ and 


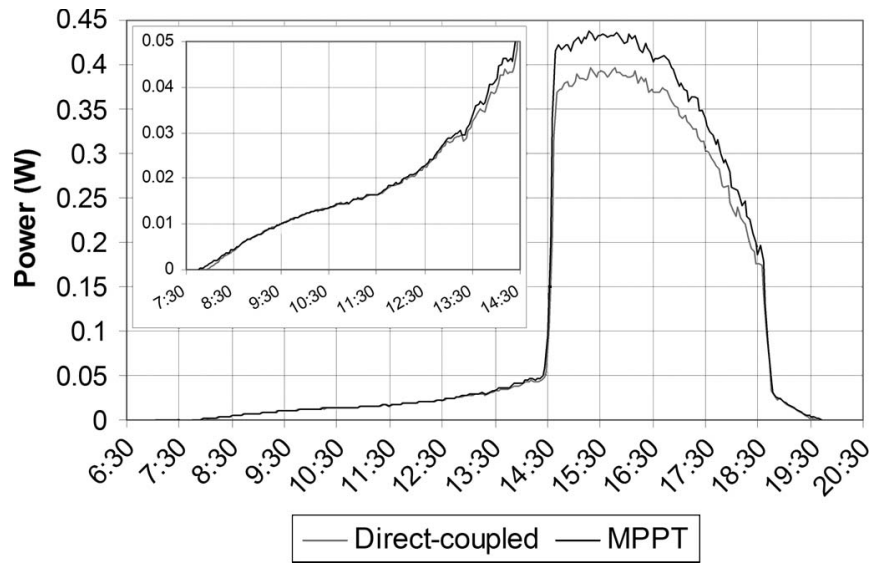

Fig. 15. Power delivered to the batteries during one day.

$800 \mathrm{~W} / \mathrm{m}^{2}$, respectively. The sudden increase of the incoming power around 14:30 indicates the incidence of the direct sun over the PV panel. The results show that the total energy collected by the MPPT circuit was $10.3 \%$ higher, even though the measured efficiency for the direct-coupled circuit was close to $85 \%$ at high-irradiance conditions.

As can be seen in the inset in Fig. 15, even at low-irradiance conditions, from 8:00 to $14: 30$, the power delivered by the proposed MPPT circuit was higher or equal to the power delivered by the direct-coupled solution. First, the MPPT circuit started to charge its batteries before the direct-coupled circuit. This circuit could not charge the batteries until the open-circuit voltage of the PV panel $\left(\mathrm{OCV}_{\mathrm{PV}}\right)$ was higher than its battery voltage $(\approx 2.4 \mathrm{~V})$, whereas the MPPT-based circuit could start to charge from a lower $\mathrm{OCV}_{\mathrm{PV}}$, corresponding to the startup voltage of the MAX1675 (1.1 V). As the irradiance increased, the operating point of the PV panel for the direct-coupled circuit approached to its MPP. As a consequence, its efficiency increased to a similar value to that of the MPPT circuit from 9:30 to 13:00, which is mainly limited by the power loss of the diode. Later, the efficiency of the MPPT rose up as the PV power increased (Fig. 12), delivering again a higher power to the batteries than the direct-coupled circuit.

We also verified that the MPPT circuit outperformed the direct-coupled solution for other weather conditions, e.g., cloudy days.

The MPP voltage of the PV panel increases for a decrease in temperature $\left(-16 \mathrm{mV} /{ }^{\circ} \mathrm{C}\right)$. Therefore, it is expected that, with cold weather, e.g., in winter, the efficiency of the directcoupled solution will decrease, whereas the MPPT circuit will still maintain a high efficiency. Then, higher energy gains are expected.

\section{CONCLUSION}

A new MPPT method that is suitable for low-power PV panels has been proposed and tested. The MPPT controller is used as an external control loop of a PFM dc/dc converter placed between the PV panel and the load. In contrast to other true MPPT controllers, such as the $\mathrm{P} \& \mathrm{O}$ method, the current has not to be measured, and no multiplier operator has to be used to calculate the power. Therefore, the control circuit is simpler, and its consumption is lower than using those conventional techniques. Consequently, a high energy efficiency can be achieved even for low-power sources.

The static and dynamic performance of the proposed MPPT method has been theoretically analyzed, and design criteria have been provided. The static performance is assessed through the power efficiency. The analysis demonstrates that a high tracking accuracy can be achieved even using low-power comparators whenever their propagation delays are matched or the charge cycle is long enough. The dynamic performance is assessed by the time response of the tracking voltage, which can be approximated by a first-order linear function.

A prototype MPPT circuit has been implemented using a commercial PFM dc/dc boost converter and low-power components for the MPPT controller. Laboratory measurements have been carried out using a custom PV array simulator in order to assess the static and dynamic performance. The tracking efficiency is higher than $99.6 \%$. The overall efficiency is higher than $92 \%$ for a PV panel power over $100 \mathrm{~mW}$. This is, in part, feasible due to the low power consumption of the MPPT controller, which is kept lower than $350 \mu \mathrm{W}$. The time response of the tracking circuit was tested to be around $1 \mathrm{~s}$. Field measurements have also been performed in order to compare the proposed solution with a direct-coupled circuit. Energy gains that are higher than $10.3 \%$ have been achieved for an ambient temperature of $26^{\circ} \mathrm{C}$. Higher gains are expected for lower temperatures.

\section{REFERENCES}

[1] V. Raghunathan, A. Kansal, J. Hsu, J. Friedman, and M. Srivastava, "Design considerations for solar energy harvesting wireless embedded systems," in Proc. 4th Int. Symp. Inf. Process. Sens. Netw., Apr. 15, 2005, pp. 457-462.

[2] X. Jiang, J. Polastre, and D. Culler, "Perpetual environmentally powered sensor networks," in Proc. 4th Int. Symp. Inf. Process. Sens. Netw., 2005, pp. 463-468.

[3] P. D. Mitcheson, E. M. Yeatman, G. K. Rao, A. S. Holmes, and T. C. Green, "Energy harvesting from human and machine motion for wireless electronic devices," Proc. IEEE, vol. 96, no. 9, pp. 1457-1486, Sep. 2008.

[4] S. Dalola, M. Ferrari, V. Ferrari, M. Guizzetti, D. Marioli, and A. Taroni, "Characterization of thermoelectric modules for powering autonomous sensors," IEEE Trans. Instrum. Meas., vol. 58, no. 1, pp. 99-107, Jan. 2009.

[5] L. Yanqiu, Y. Hongyun, S. Bo, and S. Yonghong, "Hybrid micropower source for wireless sensor network," IEEE Sensors J., vol. 8, no. 6, pp. 678-681, Jun. 2008.

[6] T. Esram and P. L. Chapman, "Comparison of photovoltaic array maximum power point tracking techniques," IEEE Trans. Energy Convers., vol. 22, no. 2, pp. 439-449, Jun. 2007.

[7] C. Alippi and C. Galperti, "An adaptive system for optimal solar energy harvesting in wireless sensor network nodes," IEEE Trans. Circuits Syst. I, Reg. Papers, vol. 55, no. 6, pp. 1742-1750, Jul. 2008.

[8] D. Dondi, A. Bertacchini, D. Brunelli, L. Larcher, and L. Benini, "Modeling and optimization of a solar energy harvester system for self-powered wireless sensor networks," IEEE Trans. Ind. Electron., vol. 55, no. 7, pp. 2759-2766, Jul. 2008.

[9] F. I. Simjee and P. H. Chou, "Efficient charging of supercapacitors for extended lifetime of wireless sensor nodes," IEEE Trans. Power Electron., vol. 23, no. 3, pp. 1526-1536, May 2008.

[10] L. Gao, R. A. Dougal, and S. Liu, "Parallel-connected solar PV system to address partial and rapidly fluctuating shadow conditions," IEEE Trans. Ind. Electron., vol. 56, no. 5, pp. 1548-1556, May 2009.

[11] M. T. Penella and M. Gasulla, "A review of commercial energy harvesters for autonomous sensors," in Proc. IMTC, Warsaw, Poland, May 1-3, 2007, pp. 1-5. 
[12] J. H. R. Enslin, M. S. Wolf, D. B. Snyman, and W. Swiegers, "Integrated photovoltaic maximum power point tracking converter," IEEE Trans. Ind. Electron., vol. 44, no. 6, pp. 769-773, Dec. 1997.

[13] B. Sahu and G. A. Rincon-Mora, "An accurate, low-voltage, CMOS switching power supply with adaptive on-time pulse-frequency modulation (PFM) control," IEEE Trans. Circuits Syst. I, Reg. Papers, vol. 54, no. 2, pp. 312-321, Feb. 2007.

[14] C. Rodriguez and G. A. J. Amaratunga, "Analytic solution to the photovoltaic maximum power point problem," IEEE Trans. Circuits Syst. I, Reg. Papers, vol. 54, no. 9, pp. 2054-2060, Sep. 2007.

[15] V. V. R. Scarpa, S. Buso, and G. Spiazzi, "Low-complexity MPPT technique exploiting the PV module MPP locus characterization," IEEE Trans. Ind. Electron., vol. 56, no. 5, pp. 1531-1537, May 2009.

[16] L. Benini and G. De Micheli, Dynamic Power Management. Design Techniques and CAD Tools. Norwell, MA: Kluwer, 1998.

[17] J. Naik, Performing Accurate PFM Mode Efficiency Measurements, Apr. 2006. [Online]. Available: http://focus.ti.com/lit/an/slva236/ slva236.pdf

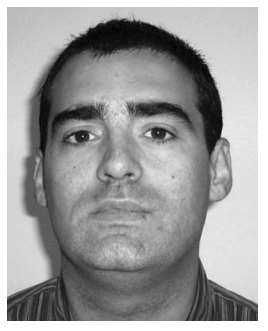

Oscar López-Lapeña received the M.S. degree in physics and the M.S. degree in electronics engineering from the Universitat de Barcelona, Barcelona, Spain, in 1994 and 1996, respectively, and the Ph.D. degree in electronics engineering from the Universitat Politècnica de Catalunya (UPC), Barcelona, in 2000 .

Since 2002, he has been an Associate Professor at UPC. His current research interests include low-power converters, control theory, and energy harvesting.

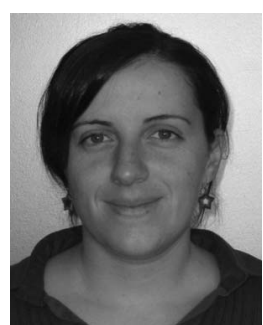

Maria Teresa Penella (S'07) received the B.Sc. and M.Sc. degrees in telecommunication from the Universitat Politècnica de Catalunya (UPC), Barcelona, Spain, in 2003 and 2005, respectively, where she is currently working toward the Ph.D. degree.

In 2007, she was with the Electronics Laboratory, Ecole Polytechnique Fédérale de Lausanne, Lausanne, Switzerland. She is currently an Assistant Professor at UPC. Her research interests include energy harvesting, energy and power conditioning, storage elements, and wireless sensor networks.

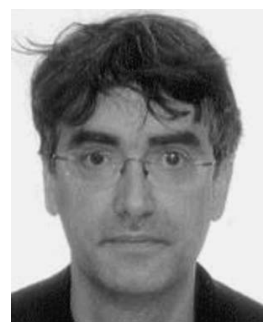

Manel Gasulla (S'97-M'01) received the M.Eng. and Ph.D. degrees in telecommunication from the Universitat Politècnica de Catalunya (UPC), Barcelona, Spain, in 1992 and 1999, respectively.

Since 1993, he has been with UPC, where he is currently an Associate Professor, engaged in teaching on analog electronics and electronic instrumentation. In 2001-2002, he was a Visiting Postdoctoral Fellow at the Electronic Instrumentation Laboratory, Delft University of Technology, Delft, The Netherlands. His research interests include capacitive sensors, sensor interfaces, wireless sensor networks, and energy-harvesting circuits and methods for low-power autonomous sensors. 